\title{
Influência da aplicação de esgoto doméstico tratado no desempenho de um sistema de irrigação
}

\author{
Rafael Oliveira Batista ${ }^{1}$, José Antonio Rodrigues de Souza ${ }^{1}$,Daniel Coelho Ferreira ${ }^{2}$
}

\begin{abstract}
RESUMO
Neste trabalho objetivou-se estudar o efeito da aplicação de esgoto doméstico tratado no desempenho de um sistema de irrigação por gotejamento. Para isso, o esgoto bruto foi submetido a uma sequência de tratamento e aplicado durante 120 horas na cultura de café, sendo avaliados a vazão do gotejador, os coeficientes de uniformidade e a distribuição. Foram também identificados os fatores causadores de obstrução. Concluiu-se que a formação de biofilme dentro dos gotejadores proporcionou redução da uniformidade de aplicação do efluente e que somente a filtração não previne a obstrução dos emissores.
\end{abstract}

Palavras-chave: Gotejadores, água residuária, obstrução.

\begin{abstract}
Effect of treated domestic sewage on the performance of a drip irrigation system

The objective of this work was to study the effect of the use of treated domestic sewage on the performance of a drip irrigation system. Crude sewage was subjected to a treatment sequence and applied for 120 hours on a coffee crop. Drip flow and coefficients of uniformity and distribution were evaluated and clogging factors were identified. The results showed that biofilm formation inside drippers decreased the uniformity of application of the effluent and that filtration alone does not prevent clogging of emitters.
\end{abstract}

Key words: Drippers, wastewater, clogging.

Recebido para publicação em outubro de 2006 e aprovado em novembro de 2009

${ }^{11}$ Engenheiros Agrícolas, Doutores. Departamento de Engenharia Agrícola, Universidade Federal de Viçosa, Av. Peter Henry Rolfs, S/N, 36570-000, Viçosa, Minas Gerais, Brasil. eng.batista@gmail.com,jarstec@yahoo.com.br

${ }^{2}$ Engenheiro-Agrônomo, Mestre. Departamento de Engenharia Agrícola, Universidade Federal de Viçosa, Av. Peter Henry Rolfs, S/N, 36570-000, Viçosa, Minas Gerais, Brasil. faraell@gmail.com 


\section{INTRODUÇÃO}

A utilização de águas residuárias na agricultura é uma alternativa para controle da poluição das águas superficiais e subterrâneas, além de uma maneira de disponibilizar água e nutrientes para as culturas, sendo de grande importância nas regiões áridas e semiáridas, onde a escassez de água faz com que se aproveitem todos os recursos hídricos (Souza, 2005). Entretanto, para que o reuso seja uma prática viável é preciso que sejam desenvolvidas técnicas de aplicação e manejo das águas (Matos, 2007).

Em virtude dos pequenos diâmetros de orifício, o entupimento de gotejadores configura-se como um dos principais problemas relacionados ao método (Pizarro Cabello, 1990; Pitts et al., 1996). Em nossas condições, uma combinação de fatores favorece o desenvolvimento de algas e bactérias nas águas utilizadas em irrigação localizada, como: predominância de temperatura na faixa ótima para o desenvolvimento microbiano; uso frequente da prática de fertirrigação; uso frequente de águas de reservatórios e canais; lançamento de esgotos em rios que são utilizados como fonte hídrica entre outros. A obstrução de gotejadores afeta a uniformidade de aplicação de água e, consequentemente, reduz a eficiência da aplicação de produtos químicos, via água de irrigação, na mesma proporção da redução de uniformidade de aplicação.

Existem vários fatores físicos, químicos e biológicos nas águas residuárias com elevado potencial de entupir os gotejadores. Por exemplo, a formação de depósitos gelatinosos, resultantes da interação entre mucilagens bacterianas, algas e zooplâncton, tem sido o fator biológico central no processo de entupimento de gotejadores quando se aplicam esgotos sanitários tratados (Ravina et al., 1992, 1997). Estudos realizados por Taylor et al. (1995) evidenciaram que as interações entre fatores físicos, químicos e biológicos foram responsáveis por $90 \%$ dos entupimentos de gotejadores. Colônias de protozoários do gênero Ciliatea e de Bryozoa plumatella foram identificadas nos gotejadores entupidos e ao longo das linhas laterais de sistemas de irrigação por gotejamento abastecidos com esgoto doméstico tratado (Ravina et al., 1992). Problema idêntico foi relatado por Sagi et al. (1995), os quais constataram nos gotejadores obstruídos apenas colônias de protozoários (Epystilus balanarum). Esses aderiram-se às paredes do equipamento de irrigação somente onde a velocidade do escoamento do efluente era inferior a $2 \mathrm{~m} \mathrm{~s}^{-1}$. Adin \& Sacks (1991) constataram ovos de Dafnia (efípios) e larvas (com $1 \mathrm{~cm}$ de comprimento) dentro de gotejadores autocompensantes que aplicavam esgoto doméstico não-filtrado.

Rav-Acha et al. (1995) verificaram diminuição de 68\% na vazão nominal de gotejadores abastecidos com esgoto doméstico tratado 60 horas após o início do experimento.
Fato similar foi descrito por Sagi et al. (1995), que identificaram colônias de protozoário ocupando 57\% da área dos gotejadores, o que acarretou queda de 38\% na vazão nominal. Ravina et al. (1992) observaram que os gotejadores autocompensantes foram mais propensos ao aumento de vazão do que os demais, devido à deterioração da membrana de autocompensação pela atividade microbiana.

Estudos realizados por vários pesquisadores demonstraram que a aplicação de águas residuárias por gotejamento acarreta sérios problemas de obstrução nos emissores. Por essa razão, no presente trabalho objetivouse avaliar o efeito da aplicação de esgoto doméstico tratado sobre a uniformidade de aplicação de água de um sistema de irrigação por gotejamento.

\section{MATERIAL E MÉTODOS}

O trabalho foi realizado na Estação-Piloto de Tratamento de Esgoto (EPTE) do Departamento de Engenharia Agrícola na Universidade Federal de Viçosa (DEA/UFV), em Viçosa, Minas Gerais.

Foi montada uma Estação Experimental Elevatória de Esgoto (EEEe) para abastecer a EPTE com esgoto doméstico bruto proveniente do conjunto residencial Condomínio Bosque Acamari, situado em Viçosa. O esgoto doméstico bruto recalcado para a EPTE foi submetido a tratamentos em três etapas distintas: tratamento preliminar (sedimentador), tratamento secundário (escoamento superficial) e tratamento terciário (lagoa de maturação).

O esgoto bruto advindo da EEEe era bombeado para o desarenador, cuja finalidade era remover os sólidos de elevada massa específica, sendo, posteriormente, conduzido por gravidade e disposto em rampas de escoamento superficial, constituído por faixas com 1,0 m de largura, 25 m de comprimento e declividade de $2 \%$, e cultivadas com capim Tifton 85 do gênero Cynodon, cujo objetivo era reduzir a carga orgânica $\left(\mathrm{DBO}_{5}\right)$. Por fim, o efluente das rampas de escoamento era conduzido para a lagoa de maturação com capacidade armazenadora de $300 \mathrm{~m}^{3}$, com dimensões de $50 \mathrm{~m}$ de comprimento por $6 \mathrm{~m}$ de largura e 1 $\mathrm{m}$ de profundidade, com a finalidade de remover os organismos patogênicos.

O efluente da lagoa de maturação foi utilizado na fertirrigação de cafeeiros da variedade Catuaí IAC 99, com dois anos de idade, cultivados no espaçamento de 2,50 m entre linhas e 0,75 m entre plantas, numa subárea de 1.400 $\mathrm{m}^{2}$, situada na EPTE.

Para aplicar o efluente da lagoa de maturação utilizaram-se um sistema de irrigação por gotejamento constituído por unidade de controle (conjunto motobomba de 3 cv, sistema de filtração automatizado e injetor de fertilizantes do tipo Venturi, com capacidade de injeção de $70 \mathrm{~L}$ $\mathrm{h}^{-1}$ ), linhas principal e de derivação, ambas em PVC, e linhas laterais com gotejadores do modelo G1. 
O Gotejador G1 era do tipo não autocompensante, com vazão nominal de 2,3 L h"-1, atuando numa faixa de pressão de serviço de 50 a $400 \mathrm{kPa}$, com labirinto de $298 \mathrm{~mm}$ de comprimento e 2 mm de largura e um único filtro secundário por gotejador, inseridos nas linhas laterais de PVC de $16 \mathrm{~mm}$ no espaçamento $0,40 \mathrm{~m}$.

As aplicações foram feitas em turno de rega variável, iniciadas em 09/05/2003 e encerradas em 12/12/2003, de modo a suprir as demandas evapotranspirométricas e parte das exigências nutricionais da cultura. Para o cálculo das lâminas a serem aplicadas utilizou-se o programa computacional IRRIGA, o qual, para efetuar o balanço de água no solo, considera as características físico-hídricas do solo, as características fenológicas da cultura e os dados climáticos da região, que foram obtidos por meio de uma estação meteorológica automática instalada na EPTE.

Os dados foram coletados apenas nas oito linhas laterais situadas no lado direito da subárea, conforme apresentado na Figura 1. A escolha justifica-se pelo fato dessas linhas apresentarem maior homogeneidade de comprimento, com variação entre 31 e 33,8 m, e valor médio de 32,5 m. No início de cada linha lateral foi instalada uma válvula para tomada de pressão, que foi mantida em $133 \mathrm{kPa}$.

Na unidade de controle foi instalado um filtro tipo membrana, autolimpante, automático, de 550 mesh e com capacidade para $5 \mathrm{~m}^{3} \mathrm{~h}^{-1}$. A retrolavagem era acionada por um sistema temporizador, a cada 30 minutos de funcionamento, durante 20 segundos. A pressão mínima requerida pela retrolavagem foi de $304 \mathrm{kPa}$.
Em cada uma das oito linhas laterais foram selecionados 24 gotejadores, igualmente espaçados, totalizando 192 emissores a serem avaliados no sistema. Para a determinação da vazão estabeleceu-se o volume aplicado pelo emissor num intervalo de tempo de três minutos. Foram realizadas quatro avaliações para determinação da uniformidade de aplicação de água nos tempos de operação de 0, 50, 100 e 120 horas, respectivamente. Os níveis da uniformidade de aplicação de água foram obtidos por meio do Coeficiente de Uniformidade de Christiansen (CUC) e Coeficiente de Uniformidade de Distribuição (CUD). As medições de pressão foram realizadas no início e final das linhas laterais, utilizando-se um manômetro.

Após as 120 horas de aplicação do esgoto doméstico pelo sistema, retiraram-se amostras de gotejadores entupidos (no início, meio e final das linhas), as quais foram enviadas ao Laboratório de Biologia Vegetal e de Microbiologia da Universidade Federal de Viçosa para identificação do material causador de obstrução.

\section{RESULTADOS E DISCUSSÃO}

Na Figura 2 está apresentada a variação do CUC e CUD ao longo do período de avaliação para os gotejadores aplicando esgoto doméstico tratado. De acordo com a Figura 2, os valores do CUC e do CUD do sistema de irrigação decresceram ao longo do tempo, devido ao entupimento dos gotejadores. Verificaram-se, nessa figura, reduções de 4,49 e 10,58\% nos valores do CUC e CUD, respectivamente, quando se estabeleceu comparação entre os tempos de funcionamento de 0 e 120 horas. No

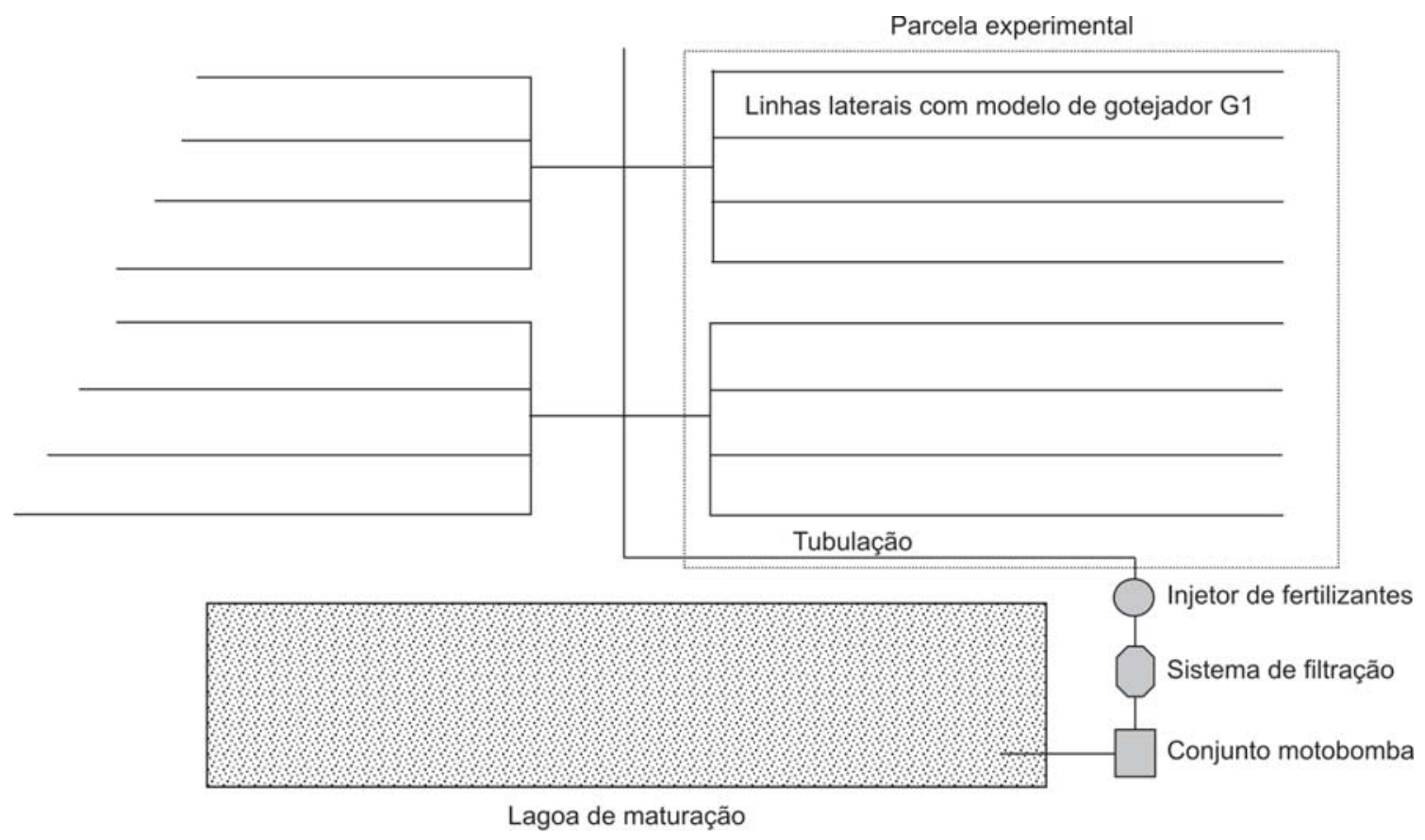

Figura 1. Esquema experimental montado em campo para avaliação do desempenho de sistema de irrigação por gotejamento aplicando esgoto doméstico de lagoa de maturação e apresentação da parcela escolhida para a coleta dos dados. 

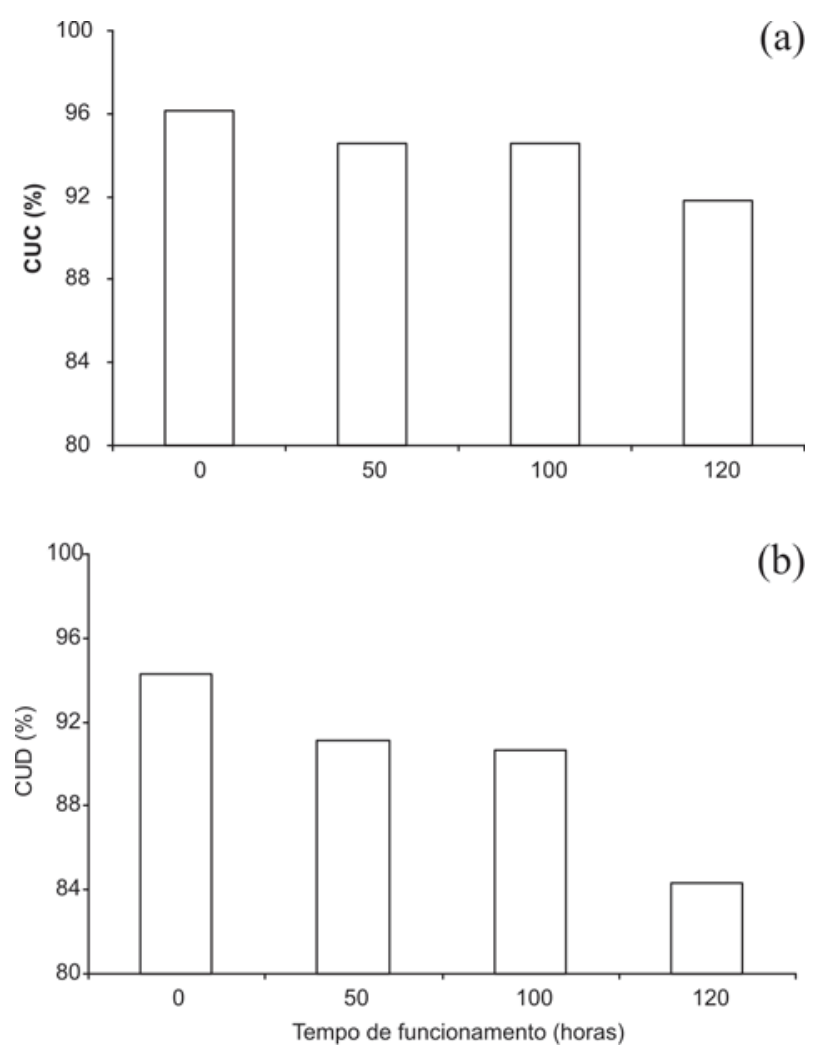

Figura 2. Valores do CUC (a) e CUD (b) do modelo de gotejador G1 nos tempos de funcionamento de 0, 50, 100 e 120 horas.

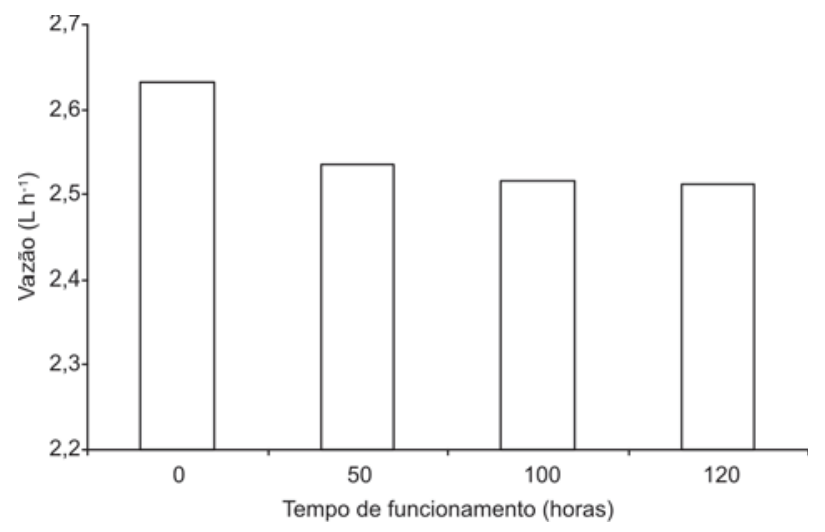

Figura 3. Valores da vazão do modelo de gotejador G1 nos tempos de funcionamento de 0, 50, 100 e 120 horas.

entanto, observou-se, também, que todos os valores de CUC foram superiores a $90 \%$, sendo, assim, classificados como excelentes, conforme Mantovani (2002). Nos tempos de funcionamento de 0,50 e 100 horas, os valores de CUD foram classificados como excelentes, segundo o critério proposto por Merriam \& Keller (1978). Porém, quando se analisou o valor do CUD no tempo de funcionamento de 120 horas, esse foi classificado como bom.

$\mathrm{O}$ entupimento dos gotejadores, além de diminuir a uniformidade de aplicação de água, propiciou decréscimo em sua vazão (Figura 3). Comparando os tempos de funcionamento de 0 e 120 horas, constatou-se redução de 4,56\% na vazão média do sistema de irrigação.
Com as avaliações da uniformidade de aplicação de água, verificou-se que o entupimento de gotejadores foi mais acentuado no final das linhas laterais. Durante a abertura do final dessas linhas, observou-se a saída de um esgoto doméstico tratado com coloração verde-escura, devido à presença de matéria orgânica.

No que se refere ao manejo da irrigação, uma consequência direta da baixa uniformidade de aplicação consiste no aumento do volume aplicado, isto é, o irrigante ao constatar a diminuição da vazão média dos gotejadores, pelo efeito do entupimento, aumenta o tempo de irrigação; logo, as plantas que receberam menor lâmina de irrigação passam a receber maior quantidade de água, de modo a atender às suas exigências hídricas. No entanto, aquelas plantas que recebiam a lâmina adequada passam a ter problema de irrigação excessiva, aumentando assim a perda por percolação (López et. al., 1992).

Por meio de análises microbiológicas e identificação visual com auxílio de microscópio, verificou-se que o material de obstrução resultou da interação entre bactérias e algas presentes na água residuária, que formaram aglomerados na forma de cocos e de pequenos bastonetes (Figura 4). Os gêneros de bactérias Clostridium, Bacillus, Pseudomonas e Enterobacter, juntamente com a ferrobactéria da espécie Cremothix sp., formaram um muco microbiano, no qual se aderiram partículas, principalmente de origem orgânica, representadas por células de algas vivas ou em decomposição. As algas predominantes pertenciam aos filos Cyanophyta (gênero Chlorococcus), Euglenophyta (gêneros Euglena e Phacus) e Chlorophyta (gêneros Selenastrum, Scenedesmus e Sphaerocystis). O biofilme se desenvolveu no interior dos gotejadores, acarretando mudanças no regime de escoamento e, consequentemente, favorecendo a deposição de partículas sobre ele. Com o aumento da massa do biofilme no interior dos gotejadores, ocorreram ao longo do tempo entupimentos parcial e total dos mesmos, reduzindo a vazão dos gotejadores e, consequentemente, diminuindo os valores de CUC e CUD.

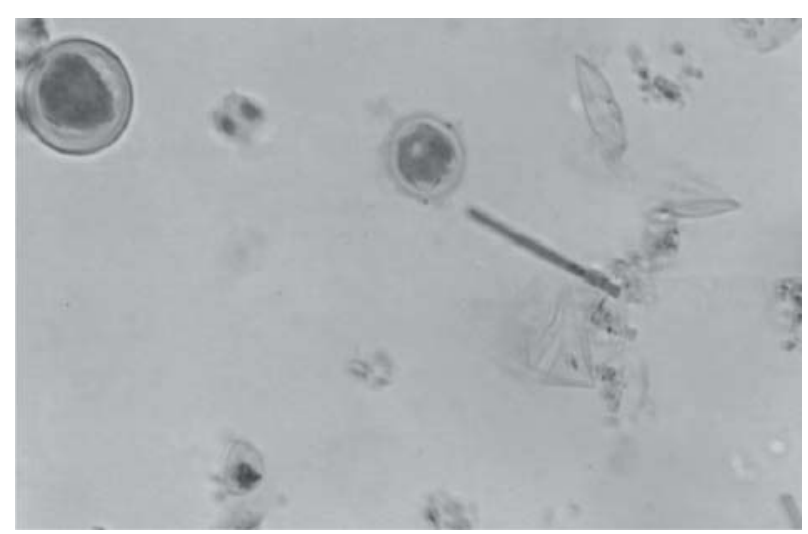

Figura 4. Análise microscópica do biofilme retirado de gotejadores entupidos, destacando os aglomerados de algas com bactérias nas formas de cocos e pequenos bastonetes. 


\section{CONCLUSÕES}

O esgoto doméstico tratado apresenta considerável potencial de obstrução de gotejadores. A formação de um biofilme, resultante da interação entre colônias de bactérias e algas, propicia entupimentos parcial e total dos gotejadores.

Ocorre decréscimo do CUC, do CUD e da vazão do gotejador avaliado com a aplicação do esgoto doméstico tratado. Após 120 horas de funcionamento, ocorrem reduções nos valores do CUC, do CUD e da vazão do sistema de irrigação com o modelo de gotejador G1 de 4,49, 10,58 e 4,56\%, respectivamente.

A filtragem com membrana de 550 mesh e abertura dos finais de linha a cada duas semanas não previne a obstrução de gotejadores.

\section{REFERÊNCIAS}

Adin A \& Sacks M (1991) Dripper-clogging factors in wastewater irrigation. Journal of the Irrigation and Drainage Engineering, 117:813-826

López JR, Abreu JMH, Regalado AP, Hernandez JFG (1992) Riego localizado. Madrid, Mundi-Prensa. 405p.

Mantovani EC (2002) Avalia. Manual do usuário. Viçosa, DEA/ UFV-PNP\&D/café EMBRAPA, 100p.

Matos AT (2007) Disposição de águas residuárias no solo. Viçosa, AEAGRI, 142p. (Caderno Didático n. 38).

Merriam JL \& Keller J (1978) Farm irrigation system evaluation: a guide for management. Logan, Utah State University, 271p.

Pitts D, Peterson K, Gilbert G \& Fastenau R (1996) Field assessment of irrigation system performance. Transactions of the ASAE, 12:307-313.

Pizarro Cabello F (1990). Riegos localizados de alta frecuencia. Madrid, Mundi-Prensa. 471p.

Rav-Acha C, Kummel M, Salamon I \& Adin A (1995) The effect of chemical oxidants on effluent constituents for drip irrigation. Water Research, 29:119-129.

Ravina I, Paz E, Sofer Z, Marcu A, Schischa A \& Sagi G (1992) Control of clogging in drip irrigation with stored reclaimed wastewater. Irrigation Science, 13:129-139.

Ravina I, Paz E, Sofer Z, Marcu A, Schischa A, Sagi G, Yechialy Z \& Lev Y (1997) Control of clogging in drip irrigation with stored treated municipal sewage effluent. Agricultural Water Management, 33:127-137.

Sagi G, Paz E, Ravina I, Schischa A, Marcu A \& Yechiely Z (1995) Clogging of drip irrigation systems by colonial protozoa and sulfur bacteria. In: $5^{\text {nd }}$ International Microirrigation Congress, Orlando. Proceedings, St. ASAE. p.250-254.

Souza JAR (2005) Desempenho de microaspersores operando com água residuária de avicultura e bovinocultura. Dissertação de Mestrado, Universidade Federal de Viçosa, Viçosa. 79p.

Taylor HD, Bastos RKX, Pearson HW \& Mara DD (1995) Drip irrigation with waste stabilization pond effluents: Solving the problem of emitter fouling. Water Science Technology, 31:417424

Rev. Ceres, Viçosa, v. 57, n.1, p. 018-022, jan/fev, 2010 